Case report

\title{
Replacing a failed implant adjacent to the implant-supported restoration in the anterior region after ridge augmentation procedure
}

\author{
Jun-Beom Park
}

Department of Pharmaceutical Sciences, College of Pharmacy, University of Michigan, Ann Arbor, MI, USA

doi: $10.1111 / j .1741-2358.2009 .00361 . x$

\section{Replacing a failed implant adjacent to the implant-supported restoration in the anterior region after ridge augmentation procedure}

Background: Dental professionals will have to deal with more implant failure and related complications due to the increase in popularity of this form of therapy.

Objectives: There have been only a few reports on replacing failed implants at the same sites. This report may provide more detailed information about the re-implantation procedure and the results to the operator and less motivated patient.

Materials and methods: The implant failure occurred after a 3-year period of loading in the anterior region. next to an implant-supported prosthesis. Ridge augmentation was performed with staged placement of an implant.

Results: The implant was re-installed after ridge augmentation with deproteinised bovine bone and absorbable membrane, with the implant-supported prosthesis functioning well up to the final evaluation. Conclusion: This case report shows the possibility of treating the failed implant in the older population using a staged approach and it may give more detailed information about the re-implantation procedure and results to the operator and less motivated patient. Further evaluations over longer periods are necessary to establish whether this procedure offers long-term benefits to patients.

Keywords: re-implantation, failure, dental implant, ridge augmentation, deproteinised bovine bone.

\section{Introduction}

Although reported success rates for dental implants are high, dental professionals will have to deal more with implant failure and related complications due to the increase in popularity of implant therapy ${ }^{1}$. There have been only a few reports on replacing failed implant at the same $\operatorname{site}^{2-4}$. Immediate replacement with a larger-diameter dental implant has been suggested as an option for a failed implant ${ }^{3}$. However, it is challenging to achieve an aesthetic result with anterior teeth having soft and hard tissue discrepancies from greater bone loss in patients who have lost implants following loading 5 .

In this case report, the implant failure occurred in the anterior region next to the implant-supported prosthesis after a 3-year period of loading.
The implant was re-installed after ridge augmentation with deproteinised bovine bone and absorbable membrane. This case report shows the possibility of treating a failed implant in the older population using a staged approach and it may provide more detailed information about the re-implantation procedure and the results to the operator and less motivated patient.

\section{Case report}

A 61-year-old female was referred to the Department of Periodontology, at Seoul National University Dental Hospital, seeking periodontal evaluation and treatment. The patient had a non-contributory medical history and was not taking any medications that were associated with a compromised soft tissue healing response. 


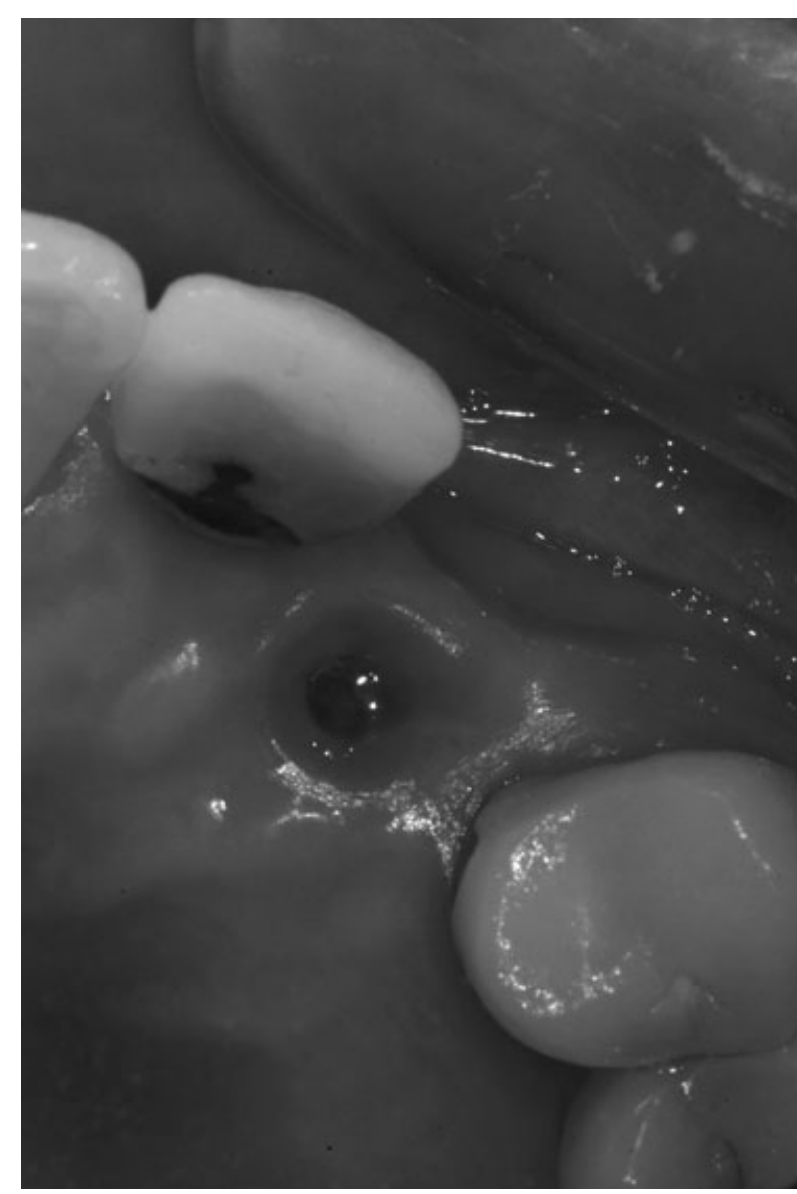

Figure 1 Initial occlusal view of previously installed implant.

The upper left canine was missing and the implant-supported prosthesis had failed after a 3-year period of loading. The upper lateral incisor was restored with an implant-supported prosthesis and the upper left first premolar had a porcelainfused-to-metal crown (Fig. 1). The patient was given a detailed explanation concerning the present state, alternative treatment plans and the procedure, and informed consent was obtained from the patient. Ridge augmentation was planned with staged placement of an implant. The soft tissue was very thin and the width of keratinised tissue on the buccal side was 1-2 mm.

Prior to surgery the patient rinsed for $60 \mathrm{~s}$ with $0.12 \%$ chlorhexidine mouth rinse (Hexamedine, Bukwang, Seoul, Korea). After local anaesthesia was achieved, a full thickness flap was reflected and an attempt was made to remove the soft tissue thoroughly within the socket by curettage (Fig. 2a). A surgical template was used to locate the desired implant position and ridge augmentation was performed accordingly (Fig. 2b). The alveolar bone was decorticated with a high-speed drill using a no. 2 round bur for the cortical plate.

The buccal defect and the extraction area were grafted with deproteinised bovine bone (Bio-Oss ${ }^{\circledR}$, Geistlich Pharm AG, Wolhusen, Switzerland) and a resorbable membrane (Bio-Gide ${ }^{\circledR}$, Geistlich Pharm AG) was shaped to completely cover the defect and bone graft in a saddle-like manner (Fig. 2c,d). Primary closure was not attempted and the exposed periosteum was covered with autogenous masticatory mucosa from the left side of the palate. The patient was placed on amoxicillin $500 \mathrm{mg}$ three times per day for 5 days, mefenamic acid $500 \mathrm{mg}$ initially then mefenamic acid $250 \mathrm{mg}$ four times per day for 5 days, and chlorhexidine digluconate $0.12 \%$ three times per day for 2 weeks. The patient was told to avoid chewing and tooth brushing the area for the first 2 weeks post-operatively. Two weeks after surgery, the sutures were removed and the grafted area was carefully cleaned with $0.12 \%$ chlorhexidine solution (Fig. 3). Healing was uneventful and the patient reported no specific symptoms.

Following 7 months of healing to allow for graft material maturation, re-entry was performed for implant placement (Fig. 4a,b). The width of the ridge was well preserved and the width of keratinised tissue on the buccal side was now $4 \mathrm{~mm}$. The grafted area healed uneventfully and soft tissue maturation was noticeable 3 months after the surgery. The $4.0 \times 12-\mathrm{mm}$ implant (Nobel Biocare AB, Göteborg, Sweden) was placed into the bone. The patient was placed on the same medication and given the same care instructions as previously. Figure 5 shows the periapical radiograph taken 4 months after implant installation.

After healing, the implant was uncovered and a healing abutment was placed in the implant. The final implant-supported crown was inserted 6 months after implant installation. The prosthesis was functioning well up to final evaluation without any probing depth and alveolar bone resorption.

\section{Discussion}

This report shows the successful treatment of a failed implant with ridge augmentation and staged placement of a new implant. Immediate replacement with a larger-diameter dental implant was not performed in this report because hard and soft tissue discrepancies from the alveolar bone loss were seen and the size of the cavity seemed to be too large to place a second implant ${ }^{3}$.

The 5-year cumulative success rates for maxillary and mandibular implants are $91.00 \%$ and $97.81 \%$, 

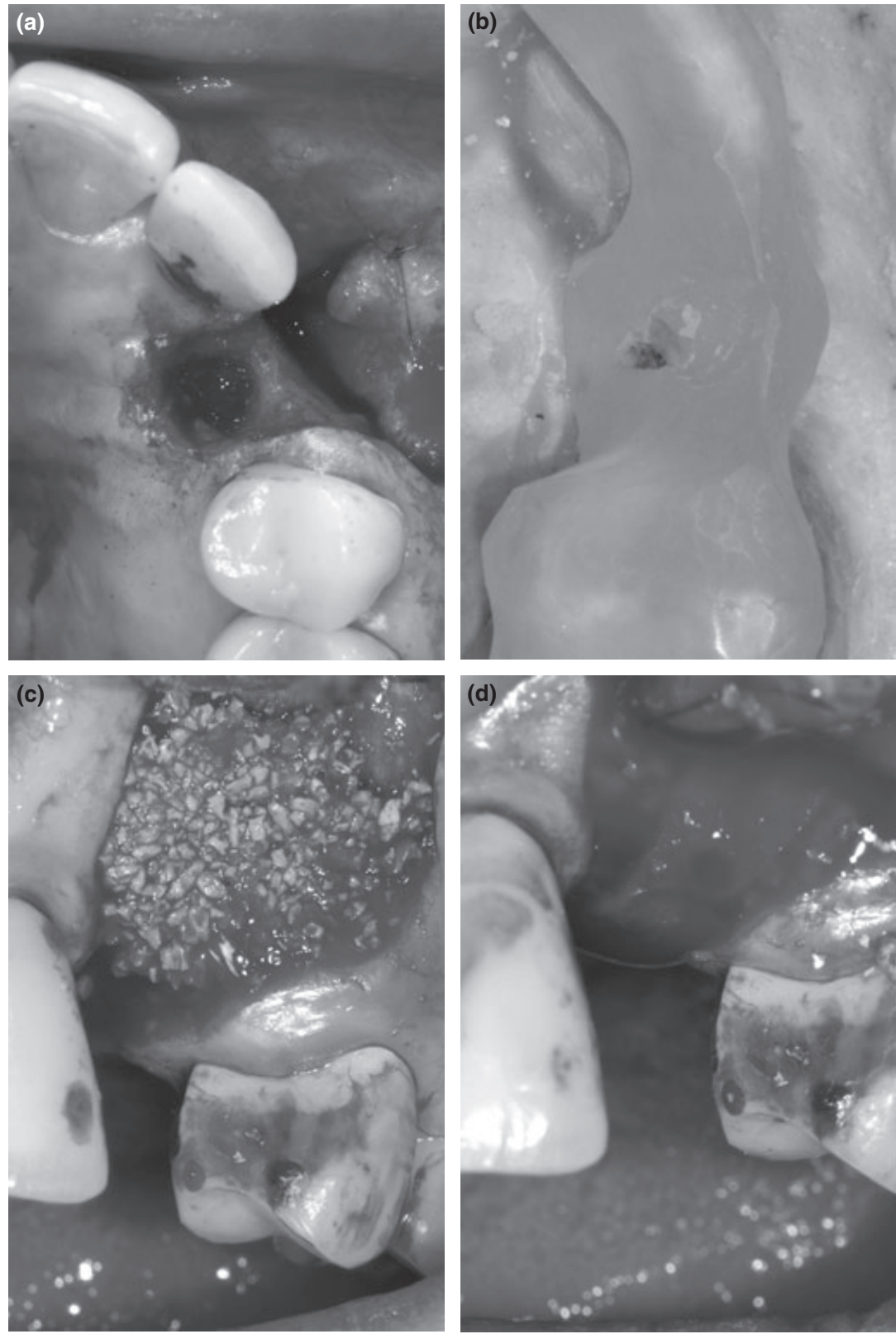

Figure 2 (a) A full thickness flap was reflected and the soft tissue was thoroughly removed within the socket by curetting. (b) A surgical template was used to locate the desired implant position and the ridge augmentation was performed accordingly. (c) The buccal defect and the extraction area were grafted with $d$ eproteinised bovine bone. (d) A resorbable membrane was shaped to completely cover the defect. respectively ${ }^{6}$, but lower success rates were observed for implants placed in older patients ${ }^{7}$. Additionally, replacement of a failed implant may result in a decline in the survival rate and it has been reported that the overall survival rate of single dental implants placed in sites of previously failed implants was $71 \%{ }^{4}$. Efforts are being made to improve the treatment outcome for the re-implantation procedures.

Meticulous removal of granulation tissue at the failed implant site was performed before ridge augmentation procedures to improve the outcome $e^{1,3}$ and an improved surface (TiUnite surface ${ }^{\mathrm{TM}}$; Nobel Biocare, Gothenburg, Sweden) was used in this report compared with the previously used machine surface. This modified surface is reported with give an enhanced bone response compared with machined implant surfaces ${ }^{8,9}$, and it was suggested that the success of a replacement may be increased ${ }^{4}$. Short implants $(\leq 10 \mathrm{~m})$ were reported to show a lower success rate $\mathrm{r}^{10,11}$, and therefore a longer implant of $12 \mathrm{~mm}$ was used in the second operation.

Deproteinsed bovine bone (DBB) was chosen as a graft material as it has many features similar to natural bone mineral in terms of structure and chemical composition $^{12}$. DBB has been shown to have osteo-conductive properties ${ }^{13}$, and the particles of DBB are reported to become integrated with newly formed bone ${ }^{14}$. 


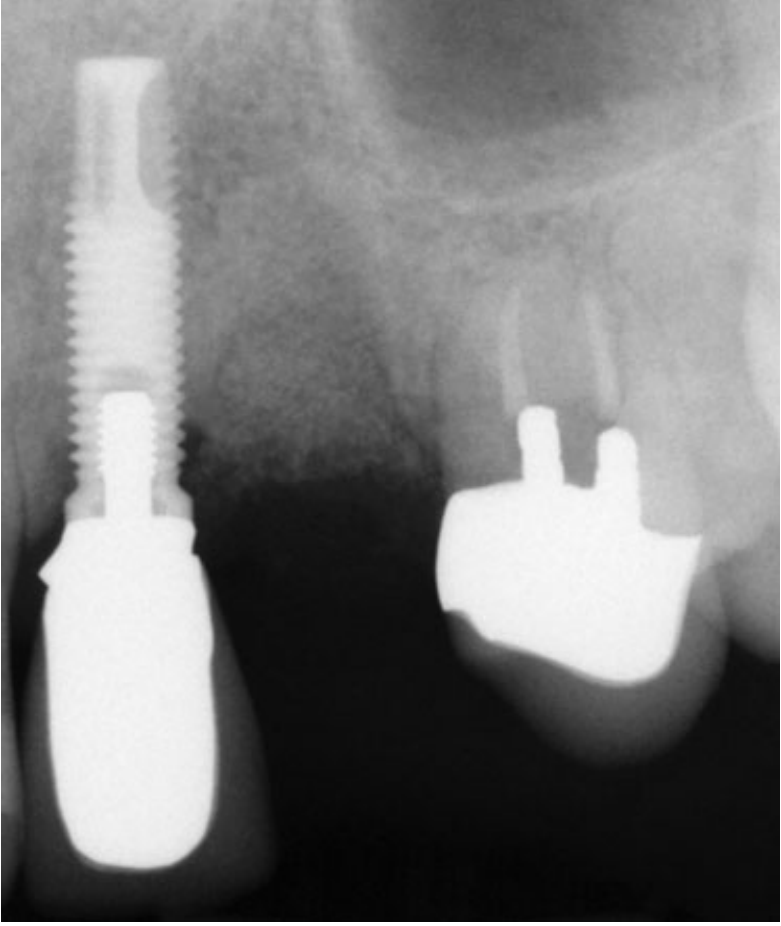

Figure 3 Two-week post-operative periapical radiograph.

Membranes have been used as a barrier to help preserve the space for new bone growth and to prevent the penetration of non-osteogenic soft tissue $^{15}$. The absorbable membrane used in this report has been shown to support and promote the proliferation of human periosteal cells ${ }^{16}$.

Decortication was carried out to enhance the healing process by promoting bleeding and allow-

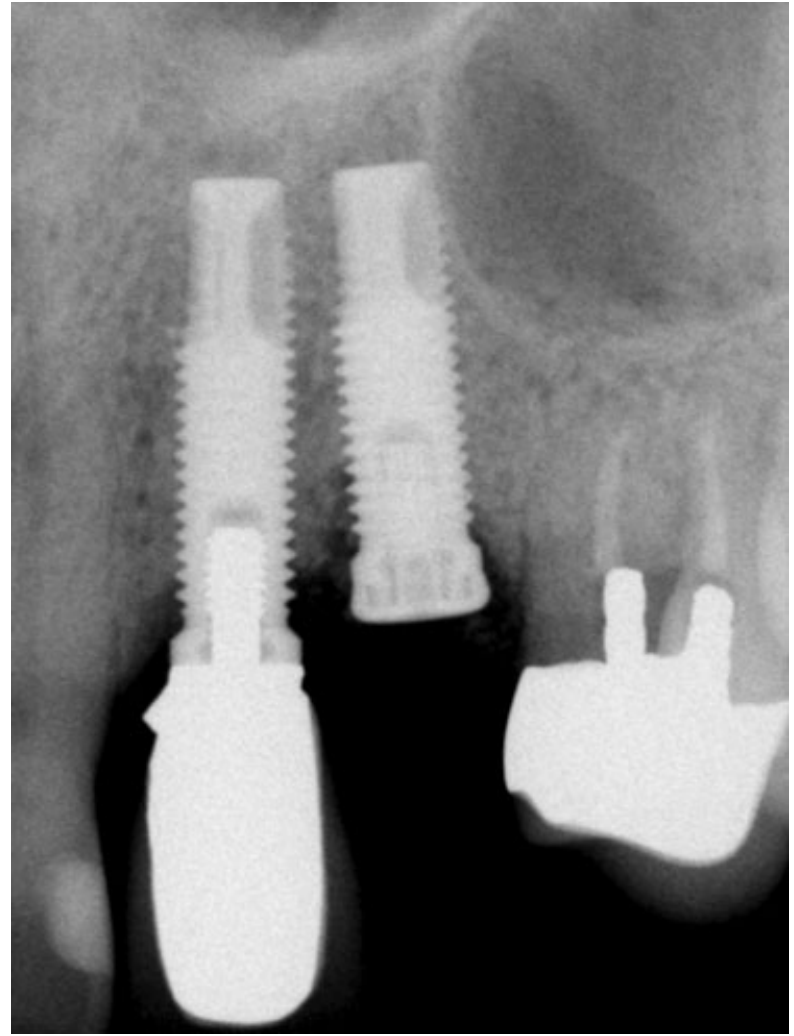

Figure 5 The periapical radiograph taken four months after implant installation.

ing progenitor cells and blood vessels to reach a bone-grafted site more readily ${ }^{17}$. There have been several reports supporting the use of decortication prior to performing ridge augmentation ${ }^{18,19}$.
Figure 4 (a) Seven-month post-operative view. (b) Occlusal view showing maturation of the soft tissue.
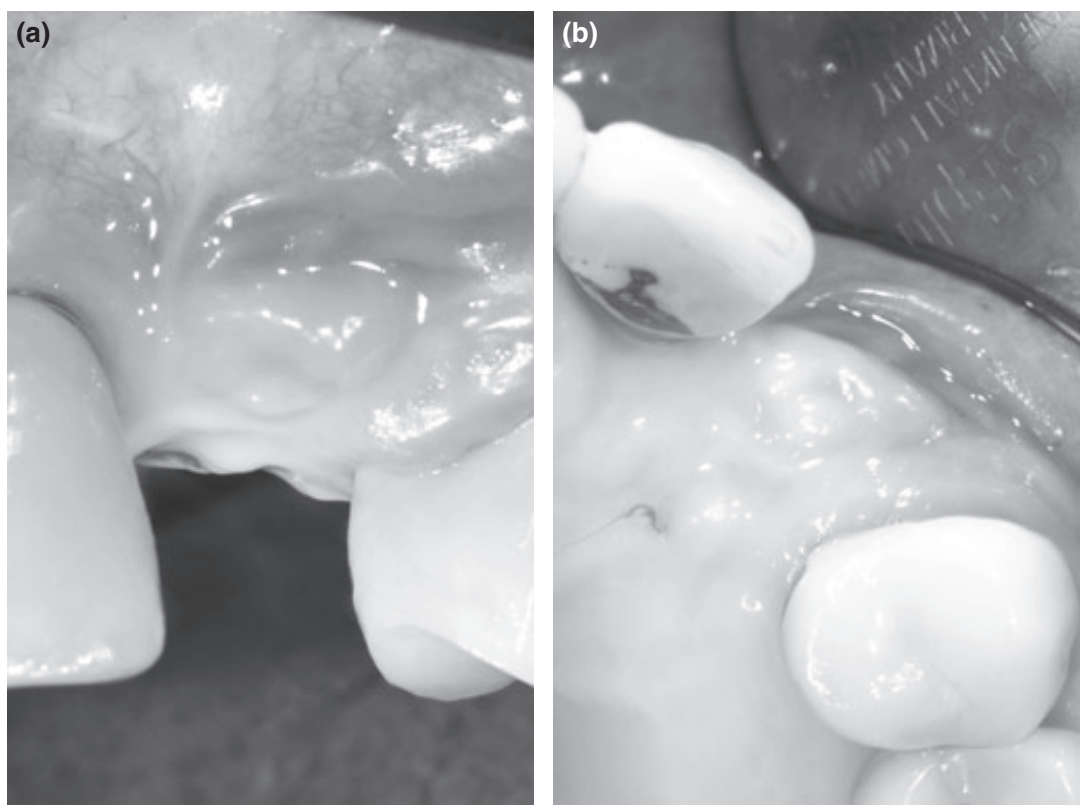
When an implant fails, patients should be informed of all the possible treatment modalities and give their consent for the most appropriate treatment option for them ${ }^{1}$. It could be suggested that a ridge augmentation procedure may be applied to the failed implant site and re-implantation can be successful with an appropriate approach. Further evaluations over longer periods are necessary to establish whether this procedure offers long-term benefits to patients.

\section{Acknowledgement and Disclosure}

The authors claim to have no financial interest in any company or any of the products mentioned in this article.

\section{References}

1. Levin L. Dealing with dental implant failures. J Appl Oral Sci 2008; 16: 171-175.

2. Glavas $\mathbf{P}$, Moses MS. Stage I indexing to replace a failed implant in an edentulous arch: a clinical report. $J$ Prosthet Dent 2003; 89: 533-535.

3. Evian CI, Cutler SA. Direct replacement of failed CP titanium implants with larger-diameter, HA-coated Ti-6Al-4V implants: report of five cases. Int $J$ Oral Maxillofac Implants 1995; 10: 736-743.

4. Grossmann Y, Levin L. Success and survival of single dental implants placed in sites of previously failed implants. J Periodontol 2007; 78: 1670-1674.

5. Hultin $M$, Fischer $\mathbf{J}$, Gustafsson A, Kallus $T$, Klinge B. Factors affecting late fixture loss and marginal bone loss around teeth and dental implants. Clin Implant Dent Relat Res 2000; 2: 203-208.

6. Gokcen-Rohlig B, Yaltirik M, Ozer S, Tuncer ED, Evlioglu G. Survival and success of ITI implants and prostheses: Retrospective Study of cases with 5-year follow-up. Eur J Dent 2009; 3: 42-49.

7. Brocard D, Barthet $\mathbf{P}$, Baysse $\mathbf{E}$ et al. A multicenter report on 1,022 consecutively placed ITI implants: a 7-year longitudinal study. Int $J$ Oral Maxillofac Implants 2000; 15: 691-700.

8. Ivanoff CJ, Widmark G, Johansson C, Wennerberg A. Histologic evaluation of bone response to oxidized and turned titanium micro-implants in human jawbone. Int J Oral Maxillofac Implants 2003; 18: $341-348$.

9. Huang YH, Xiropaidis AV, Sorensen RG, Albandar JM, Hall J, Wikesjo UM. Bone formation at titanium porous oxide (TiUnite) oral implants in type IV bone. Clin Oral Implants Res 2005; 16: 105111.
10. Duyck J, Naert I. Failure of oral implants: aetiology, symptoms and influencing factors. Clin Oral Investig 1998; 2: 102-114.

11. Mardinger O, Oubaid S, Manor Y, Nissan J, Chaushu G. Factors affecting the decision to replace failed implants: a retrospective study. J Periodontol 2008; 79: 2262-2266.

12. Accorsi-Mendonca T, Conz MB, Barros TC, de Sena LA, Soares Gde A, Granjeiro JM. Physicochemical characterization of two deproteinized bovine xenografts. Braz Oral Res 2008; 22: 5-10.

13. Traini T, Valentini P, Iezzi G, Piattelli A. A histologic and histomorphometric evaluation of anorganic bovine bone retrieved 9 years after a sinus augmentation procedure. J Periodontol 2007; 78: 955-961.

14. Botticelli D, Berglundh T, Lindhe J. The influence of a biomaterial on the closure of a marginal hard tissue defect adjacent to implants. An experimental study in the dog. Clin Oral Implants Res 2004; 15: 285-292.

15. Fiorellini JP, Kim DM, Nakajima Y, Weber HP. Osseointegration of titanium implants following guided bone regeneration using expanded polytetrafluoroethylene membrane and various bone fillers. Int $J$ Periodontics Restorative Dent 2007; 27: 287-294.

16. Warnke PH, Douglas T, Sivananthan S, Wiltfang J, Springer I, Becker ST. Tissue engineering of periosteal cell membranes in vitro. Clin Oral Implants Res 2009; 20: 761-766.

17. Greenstein G, Greenstein B, Cavallaro J, Tarnow D. The role of bone decortication in enhancing the results of guided bone regeneration: a literature review. J Periodontol 2009; 80: 175-189.

18. Simion M, Dahlin C, Rocchietta I, Stavropoulos A, Sanchez R, Karring T. Vertical ridge augmentation with guided bone regeneration in association with dental implants: an experimental study in dogs. Clin Oral Implants Res 2007; 18: 86-94.

19. Simion M, Rocchietta I, Kim D, Nevins M, Fiorellini $\mathbf{J}$. Vertical ridge augmentation by means of deproteinized bovine bone block and recombinant human platelet-derived growth factor-BB: a histologic study in a dog model. Int $J$ Periodontics Restorative Dent 2006; 26: 415-423.

Correspondence to:

Jun-Beom Park, DDS, MSD, PhD, Department of Pharmaceutical Sciences, College of Pharmacy, University of Michigan, 1664 McIntyre Drive, Ann Arbor, MI, 48105 USA.

Tel.:+1 7345659775

E-mail: jbassoonis@yahoo.co.kr 